\title{
CD8 Encephalitis in a Treatment-Naive and a Virologically Suppressed Patient with HIV - ERRATUM
}

\author{
Ali Cheema, Kristen Mathias, Christine Bui, Steven Richard Dunham, \\ J. Clay Goodman, Hana M. El Sahly
}

Keywords: HIV, encephalitis, inflammatory diseases, erratum

doi:10.1017/cjn.2019.326

Can J Neurol Sci. 2020; 47: 151

doi: https://doi.org/10.1017/cjn.2019.288, Published by Cambridge University Press, 30 August 2019

The above article ${ }^{1}$ published with an incorrect affiliation for Steven Richard Dunham.

Steven Richard Dunham's affiliation is as follows:

Department of Neurology, Baylor College of Medicine, Houston, TX, USA

The original article has been corrected online to rectify this error.

\section{REFERENCE}

1. Cheema A, Mathias K, Bui C, et al. CD8 encephalitis in a treatment-naive and a virologically suppressed patient with HIV. Can J Neurol Sci. 2019;46(6):773-5. doi: 10.1017/ cjn.2019.288. 